\title{
K604, a specific acyl-CoA:cholesterol acyltransferase 1 inhibitor, suppresses proliferation of U251-MG glioblastoma cells
}

\author{
TAKUJI OHMOTO $^{1}$, KAZUCHIKA NISHITSUJI ${ }^{1}$, NOBUYUKI YOSHITANI ${ }^{1}$, \\ MAKOTO MIZUGUCHI $^{1}$, YUTO YANAGISAWA ${ }^{2}$, HIROYUKI SAITO $^{2}$ and NAOMI SAKASHITA ${ }^{1}$ \\ ${ }^{1}$ Department of Human Pathology, Institute of Health Biosciences, The University of Tokushima Graduate School, \\ Tokushima 770-8503; ${ }^{2}$ Department of Physical Pharmaceutics, Institute of Health Biosciences and \\ Graduate School of Pharmaceutical Sciences, The University of Tokushima, Tokushima 770-8505, Japan
}

Received October 29, 2014; Accepted July 23, 2015

DOI: $10.3892 / \mathrm{mmr} .2015 .4200$

\begin{abstract}
Glioblastoma is the most aggressive type of brain tumor and has a poor prognosis. Increased levels of cholesteryl ester and simultaneous expression of acyl-CoA:cholesterol acyltransferase 1 (ACAT1) in tumor cells indicated that cholesterol esterification is critical to tumor growth. The present study confirmed that human glioblastoma tissues as well as the glioblastoma cell line U251-MG showed significant expression of ACAT1. ACAT1 expression in U251-MG cells increased in a cell proliferation-dependent manner. K604, a selective ACAT1 inhibitor, suppressed the proliferation of U251-MG cells and downregulated the activation of Akt and extracellular signal-regulated kinase in proliferating glioblastoma cells. These results suggested that ACAT1 may be a therapeutic target for the treatment of glioblastoma, with K604 as an effective therapeutic agent.
\end{abstract}

\section{Introduction}

The role of cholesterol in malignancy has been recognized for numerous decades. In 1933, Roffo reported that cell cholesterol levels were associated with carcinogenesis (1). Malignant tumors were also reported to contain elevated levels of neutral lipids, particularly phospholipids and cholesteryl ester as compared to those in native, healthy tissues from

Correspondence to: Dr Kazuchika Nishitsuji, Department of Human Pathology, Institute of Health Biosciences, The University of Tokushima Graduate School, 3-18-15 Kuramotocho, Tokushima 770-8503, Japan

E-mail: nishitsuji@tokushima-u.ac.jp

Abbreviations: ACAT, acyl-CoA:cholesterol acyltransferase; ERK, extracellular-signal-regulated kinase; HE, hematoxylin-eosin; DAB- $\mathrm{H}_{2} \mathrm{O}_{2}, 3,3$ '-diaminobenzidine $\mathrm{H}_{2} \mathrm{O}_{2}$; TCA, trichloroacetic acid; TBS, tris-buffered saline; TBS-T, TBS supplemented with $0.1 \%$ Tween 20; ANOVA, analysis of variance

Key words: acyl-CoA:cholesterol acyltransferase 1, glioblastoma, acyl-CoA:cholesterol acyltransferase inhibitor, cell proliferation, cholesteryl ester which the tumors originated (2). Furthermore, tissues of clear cell renal cell carcinoma, a representative type of malignant kidney tumor, contained increased amounts of cholesteryl esters compared with those in normal kidneys (3). Cholesteryl ester is synthesized by acyl-CoA:cholesterol acyltransferase (ACAT), which is a membrane-bound microsomal enzyme that catalyzes cholesteryl ester formation by using long-chain fatty acyl-CoA and cholesterol as substrates $(4,5)$. Of the two human ACAT isoforms, ACAT1 and ACAT2, ACAT1 is expressed in numerous organs and tissue types, including the brain (6). Previous studies showed that cholesteryl ester levels in glioma tissues were higher than those in normal brain tissues $(7,8)$. Glioma is the most common type of malignant brain tumor and is derived from glial cells or their precursors. Glioma is classified as grade I-IV on the basis of its histological anaplasia and the degree of tumor cell proliferation; the diffuse invasion of brain tissue by glioma cells results in incomplete surgical resection and frequent post-surgical tumor recurrence (9). Low-grade glioma occasionally transforms into an aggressive form, which has a poor prognosis (10). Therefore, an effective therapeutic strategy to reduce the proliferation of glioma cells after surgical resection is necessary.

The present study analyzed human glioblastoma tissues for ACAT1 expression. To investigate the cancer-promoting roles of ACAT1 in glioblastoma, the human glioblastoma cell line U251-MG was used in order to determine whether K604 (Fig. 1), a specific ACAT1 inhibitor which does not affect the systemic cholesterol metabolism (11), suppresses the proliferation of U251-MG cells. Furthermore, to investigate the detailed molecular mechanism of the activity of ACAT1 in glioma, the effects of K604 on the phosphorylation of Akt and extracellular-signal-regulated kinase 1/2 (ERK1/2), which have a key role in cell proliferation and survival $(12,13)$, were assessed. The results of the present study, as well as those of a previous study (14) supported that ACAT1 may be a promising therapeutic target for glioblastoma.

\section{Materials and methods}

Materials. K604 was kindly provided by Kowa Company Ltd. (Tokyo, Japan). Rabbit polyclonal anti-actin antibody (cat. no. A2066), mouse monoclonal anti-phosphorylated 
ERK1/2 antibody (cat. no. M8159), SDS, polyacrylamide, bovine serum albumin, saponin, poly-L-lysine and dimethyl sulfoxide were purchased from Sigma-Aldrich (St. Louis, MO, USA). An rabbit polyclonal anti-phosphorylated Akt antibody (cat, no. 9271), rabbit monoclonal anti-pan Akt antibody (cat. no. 4691) and rabbit monoclonal anti-ERK1/2 antibody (cat. no. 4695) were purchased from Cell Signaling Technology (Beverly, MA, USA). Rabbit polyclonal anti-ACAT1 $(1: 1,000)$ antibody was prepared as previously described (15). Trichloroacetic acid (TCA) was obtained from Wako Pure Chemical Industries, Ltd. (Osaka, Japan).

Cell culture. U251-MG cells, obtained from American Type Culture Collection (Manassas, VA, USA) were cultured in Dulbecco's modified Eagle's medium (Sigma-Aldrich) supplemented with $10 \%$ heat-inactivated fetal bovine serum (Lonza Group Ltd, Basel, Switzerland), $100 \mathrm{U} / \mathrm{ml}$ penicillin (SigmaAldrich) and $100 \mathrm{mg} / \mathrm{ml}$ streptomycin (Sigma-Aldrich) at $37^{\circ} \mathrm{C}$ in an atmosphere containing $5 \% \mathrm{CO}_{2}$.

Immunohistochemistry. The present study was approved by the Ethics Committee of the Tokushima University Hospital (Tokushima, Japan). Formalin-fixed, paraffin-embedded specimens of human glioblastoma tissues were obtained from three patients (70-90 years old) in July 2010, December 2013 and March 2014. No normal brain tissues were examined. The tumors were classified as grade IV. Tokushima University Hospital. Informed consent was obtained from the patient with the presence of a family member as a witness. Paraffin blocks of tissues were cut into 3-mm slices using a slide microtome (Leica SM2010 R; Leica Microsystems, Wetzlar, Germany). After the tissue sections were de-paraffinized in xylene (Wako Pure Chemical Industries, Ltd.) and re-hydrated in decreasing concentrations of ethanol (Wako Pure Chemical Industries, Ltd.) they were incubated with $0.1 \mathrm{M}$ sodium citrate $(\mathrm{pH} 6.0$; Wako Pure Chemical Industries, Ltd. at $95^{\circ} \mathrm{C}$ for $20 \mathrm{~min}$ for antigen retrieval. Endogenous peroxidases were blocked with $0.9 \%$ hydrogen peroxide (Wako Pure Chemical Industries, Ltd.), followed by blocking with $10 \%$ bovine serum albumin (Sigma-Aldrich) in phosphate-buffered saline (PBS) for $30 \mathrm{~min}$. The sections were incubated with rabbit polyclonal anti-ACAT1 antibody $(1: 1,000)$ for $1 \mathrm{~h}$ at room temperature. After removal of primary antibodies by washing the sections for five times with PBS, the sections were reacted with the secondary antibody Histofine Simple Stain MAX PO (R) (Nichirei Bioscience, Inc., Tokyo, Japan) for $30 \mathrm{~min}$. For visualization of the reaction, a 3,3'-diaminobenzidine $\mathrm{H}_{2} \mathrm{O}_{2}$ substrate (DAB- $\mathrm{H}_{2} \mathrm{O}_{2}$; Dako, Glostrup, Denmark) was applied to the sample. The sections were then counterstained with Mayer's hematoxylin solution and coverslips were mounted with Entellan mounting medium (Merck, Kenilworth, NJ, USA). Immunostained samples were analyzed using a BX51 light microscope and a DP-25 digital camera (Olympus Corporation, Tokyo, Japan). For histological examination, de-paraffinized tissue sections were also stained with hematoxylin and eosin (HE; cat. nos. 8650 and 8659; Sakura Finetek Japan, Tokyo, Japan).

Immunocytochemistry. U251-MG cells were plated on poly-L-lysine-coated coverslips at various densities $(0.75,2.25$

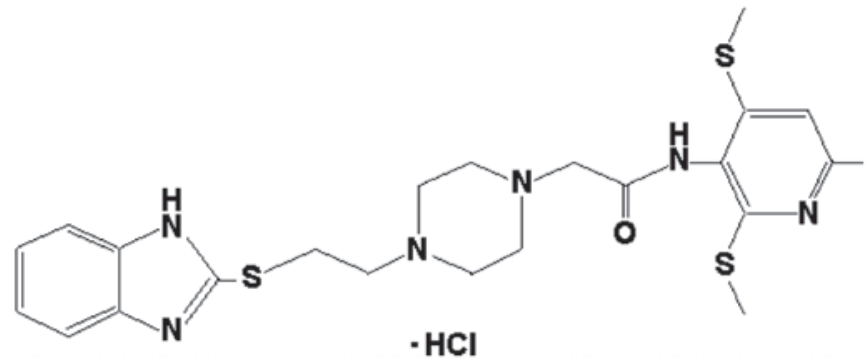

Figure 1. Chemical structure of 2-[4-[2-(benzimidazol-2-ylthio) ethyl] piperazin-1yl]- $N$-[2,4-bis(methylthio)-6-methyl-3-pyridyl]acetamide (K604).

and $5.25 \times 10^{4}$ cells $/ \mathrm{cm}^{2}$ ) followed by culture for $12 \mathrm{~h}$. The cells were fixed with $4 \%$ paraformaldehyde (Wako Pure Chemical Industries Ltd.) for $20 \mathrm{~min}$ at room temperature. After the cells were washed with PBS three times, they were blocked and permeabilized with 10\% normal goat serum (Thermo Fisher Scientific Inc., Waltham, MA, USA) and $0.05 \%$ saponin (Wako Pure Chemical Industries, Ltd.) in PBS at room temperature for $20 \mathrm{~min}$. The cells were then incubated with the primary antibody (1:250), for $30 \mathrm{~min}$ at room temperature, washed with PBS, reacted with a secondary antibody [Histofine Simple Stain MAX PO (R); Nichirei Bioscience, Inc.] and visualized after incubation with DAB- $\mathrm{H}_{2} \mathrm{O}_{2}$ (Dako) solution. The specimens were mounted with Entellan mounting medium and examined with a BX51 light microscope and a DP-25 digital camera.

Cell proliferation assay. Cell proliferation was analyzed using an MTT assay (16). U251-MG cells were plated at densities of $0.75-6 \times 10^{4}$ cells $/ \mathrm{cm}^{2}$ in a 24 -well plate. The cells were cultured for $12 \mathrm{~h}$ and then treated with 1 or $2 \mathrm{mM} \mathrm{K} 604$ for $48 \mathrm{~h}$. Cell viability was quantitatively determined by means of MTT reduction. In brief, MTT (Wako Pure Chemical Industries, Ltd.) was added to each well to a final concentration of $0.5 \mathrm{mg} / \mathrm{ml}$. After $3 \mathrm{~h}$ of incubation, the medium was removed and the precipitated formazan crystals were dissolved in dimethyl sulfoxide (Wako Pure Chemical Industries, Ltd.). An Infinite M200 microplate reader (Tecan Japan Co., Ltd, Kanagawa, Japan) was used to measure the absorbance values of the formazan crystals at $570 \mathrm{~nm}$, with the absorbance at $650 \mathrm{~nm}$ then being subtracted.

Western blot analysis. U251-MG cells were plated in 6-cm dishes (cat. no. 353002; Corning Life Sciences, Flintshire, UK) at various densities $\left(0.75,2.25\right.$ and $5.25 \times 10^{4}$ cells $\left./ \mathrm{cm}^{2}\right)$ and cultured for $12 \mathrm{~h}$. Certain cell samples were treated with K604 (2 or $5 \mu \mathrm{M})$ for $24 \mathrm{~h}$. Whole-cell lysates were prepared via TCA precipitation (17). Briefly, the cells were washed three times with PBS and were then treated with $10 \%(\mathrm{w} / \mathrm{v})$ TCA (Wako Pure Chemical Industries, Ltd.) in PBS. After the samples were incubated on ice for $30 \mathrm{~min}$, they were centrifuged at $1,000 \mathrm{xg}$ for $5 \mathrm{~min}$ at $4^{\circ} \mathrm{C}$. The precipitated proteins were dissolved in SDS-PAGE sample buffer containing 0.125 M Tris-HCl, 4\% (w/v) SDS (Sigma-Aldrich), 20\% (v/v) glycerol (Wako Pure Chemical Industries, Ltd.) and 0.01\% (w/v) bromophenol blue (Wako Pure Chemical Industries, Ltd.) for preparation of cell lysates. The protein concentration was determined using XL Bradford assay (Apro Science, 
A

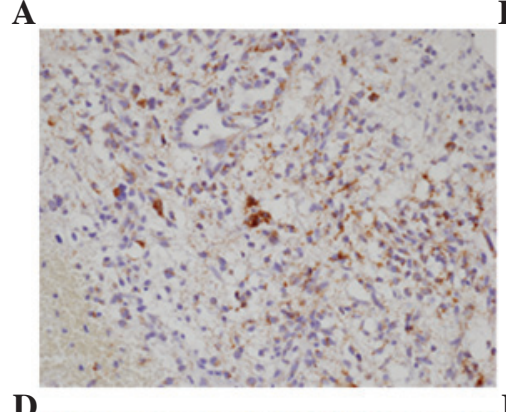

B

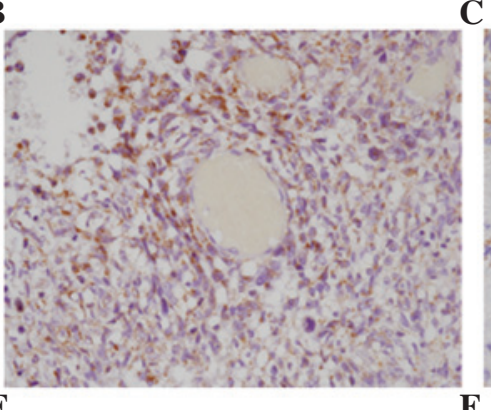

C
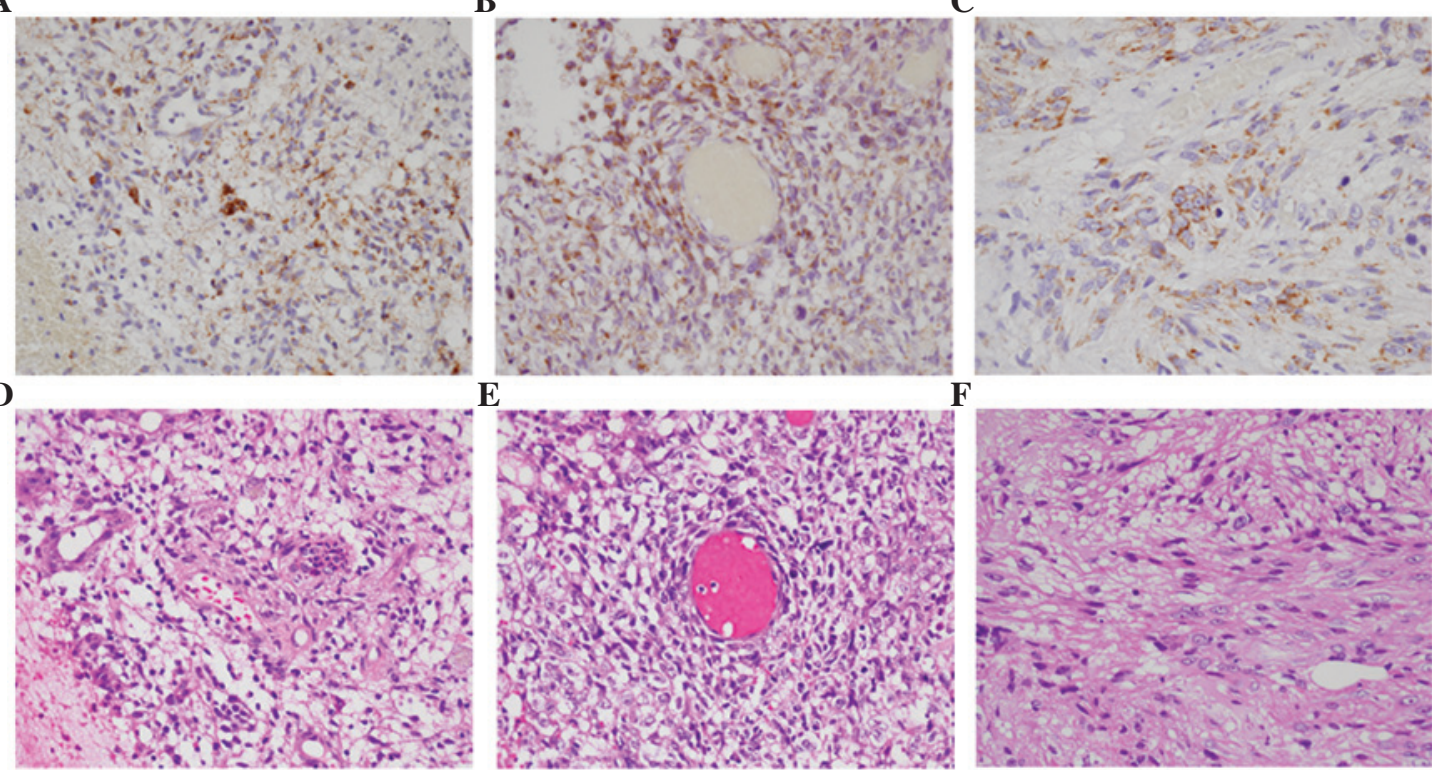

.
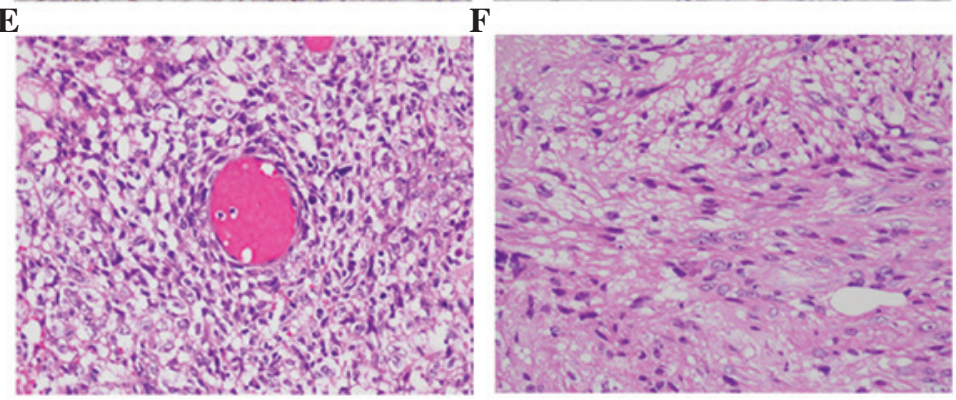

Figure 2. Expression of ACAT1 in human glioblastoma. Sections of individual human glioblastoma tissue samples were stained with anti-ACAT1 antibody. Tissue samples were also prepared as HE-stained sections for histological evaluation (magnification, x100; x10 occular lens; x10 objective lens). (A-C) Anti-ACAT1 antibody staining demonstrates ACAT1 expression, and (D-F) HE staining was performed for histological characterization of the glioblastoma. (A) and (D), (B) and (E), and (C) and (F) are from the same tissue samples, respectively. Each photomicrograph was captured with a $\mathrm{x} 40$ objective lens. HE, hematoxylin and eosin; ACAT, acyl-CoA:cholesterol acyltransferase.

A

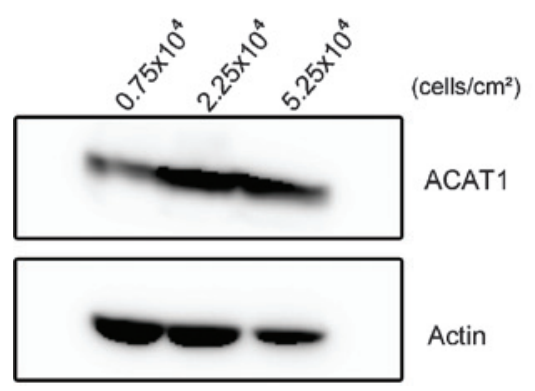

B

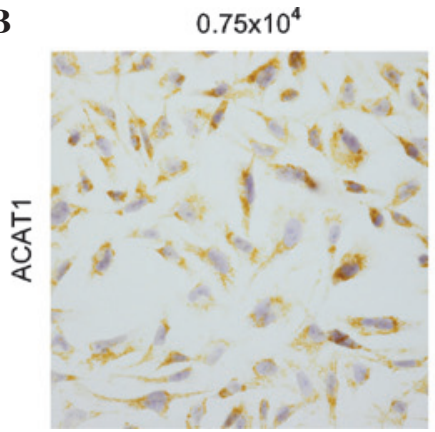

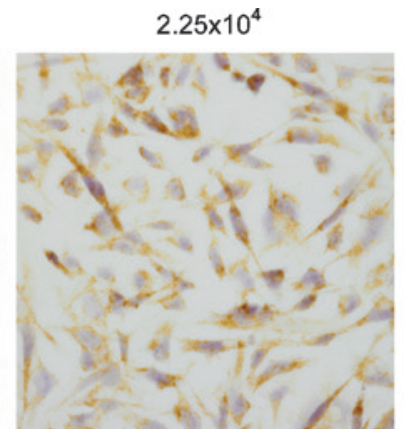

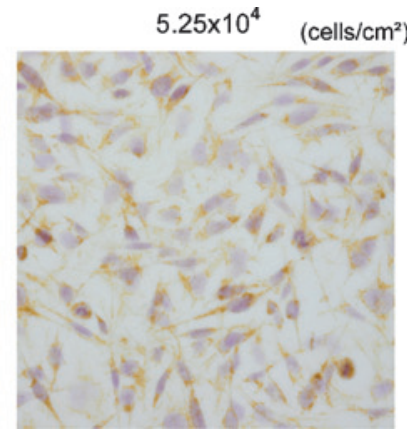

Figure 3. Cell growth-dependent expression of ACAT1 in U251-MG cells. (A) Western blot analysis of ACAT1 in U251-MG cells seeded at the indicated cell densities The blot is representative of two individual experiments. $\beta$-actin was used as a loading control. (B) Immunohistochemical staining for ACAT in U251-MG cells seeded at various densities. Each image was captured at magnification, x400, using a x10 objective lens and x40 objective lens. ACAT, acyl-CoA:cholesterol acyltransferase.

Tokushima, Japan) and $10 \mu \mathrm{g} /$ lane were subjected to $10 \%$ SDS-PAGE (Wako Pure Chemical Industries Ltd.) and transferred onto 0.45- $\mu \mathrm{m}$ Immobilon-P membranes (Millipore, Billerica, MA, USA). After the membranes were blocked for $1 \mathrm{~h}$ in $1 \%$ BSA and $3 \%$ nonfat dry milk (BD Biosciences, Franklin Lakes, NJ, USA) in Tris-buffered saline (TBS) supplemented with $0.1 \%$ Tween 20 (TBS-T; Cell Signaling Technology, Inc.), they were incubated with the following primary antibodies: Anti-ACAT1 (1:1,000), anti-Akt (1:1,000), anti-phosphorylated Akt $(1: 1,000)$, anti-ERK1/2 antibody $(1: 1,000)$, anti-phosphorylated ERK1/2 $(1: 1,000)$ and anti- $\beta$-actin $(1: 1,000)$ at room temperature for $1 \mathrm{~h}$. The membranes were then washed three times with TBS-T, after which they were incubated with a horseradish peroxidase-labeled anti-rabbit or anti-mouse secondary antibody (Cell Signaling Technology). After the membranes were washed with TBS-T, blots were visualized using the enhanced chemiluminescence reagent ImmunoStar LD (Wako Pure Chemical Industries, Ltd). Protein expression was normalized to that of $\beta$-actin. The blots were analyzed by using an LAS-3000 luminescent image analyzer (Fujifilm, Tokyo, Japan) and Image J software (version 1.47; National Institutes of Health, Bethesda, MD, USA).

Statistical analysis. Data are expressed as the mean \pm standard error of the mean. Data were analyzed via one-way analysis of variance with the appropriate control and K604-treated variables, followed by a non-parametric Dunnett's test, using the statistical package R (version 3.1.0; available as a free download from http://www.r-project.org). $\mathrm{P}<0.05$ was considered to indicate a statistically significant difference.

\section{Results}

ACAT1 is expressed in human glioblastoma tissues. To assess the expression of ACAT1 in human glioma, the present study first evaluated surgically resected glioblastoma tissues 

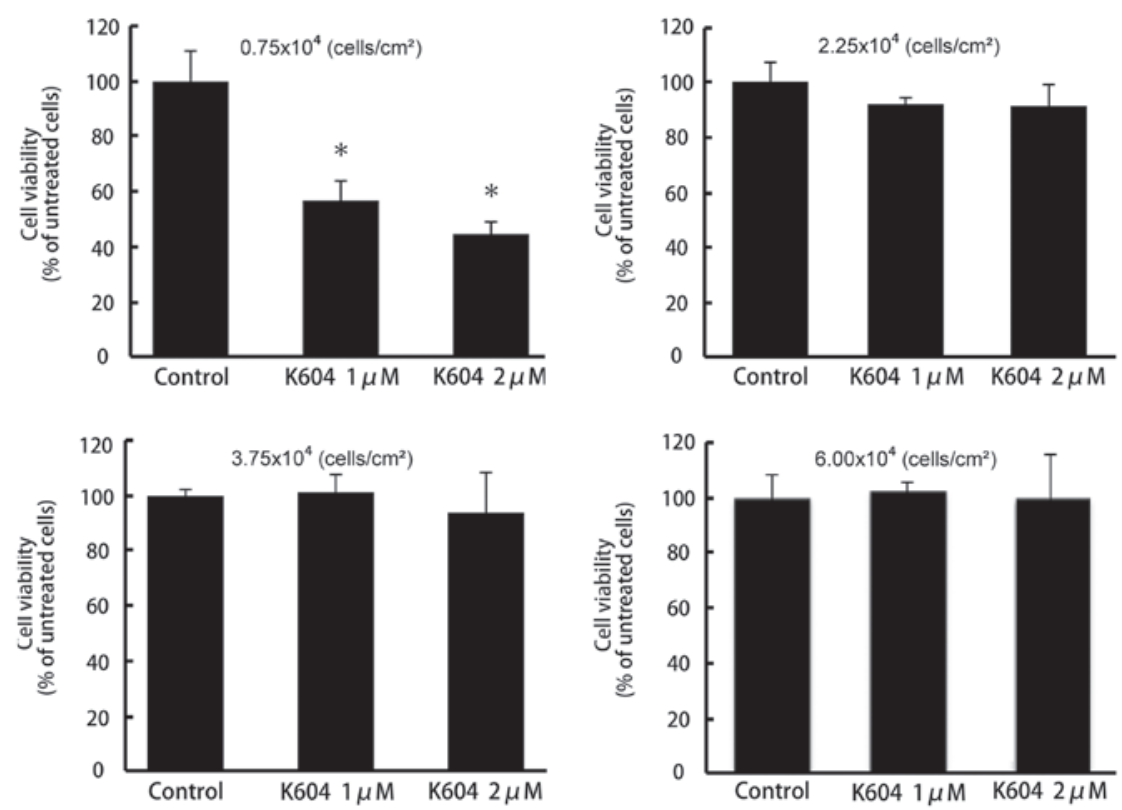

Figure 4. Suppression of U251-MG-cell proliferation by pharmacological acyl-CoA:cholesterol acyltransferase 1 inhibition. U251-MG cells seeded at the indicated cell densities were treated with K604 for $48 \mathrm{~h}$ after being cultured for $12 \mathrm{~h}$. Cell viability was determined by an MTT assay. Data are expressed as mean \pm standard error of the mean $(\mathrm{n}=3)$. ${ }^{*} \mathrm{P}<0.001$ vs. control.

obtained from three patients. According to the World Health Organization grading system (18), glioma is classified as a grade-IV brain tumor on the basis of immunohistochemical data. As shown in Fig. 2, abundant ACAT1 expression was confirmed in all human glioblastoma tissue samples examined (Fig. 2A-C). Histological analysis by HE staining confirmed that all tumor specimens were glioblastoma, as they showed marked cellular anaplasia and high cell density (Fig. 2D-F).

Expression of ACAT1 in U251-MG cells is cell density-dependent. Next, the present study explored ACAT1 expression in the human glioblastoma cell line U251-MG. Whole-cell lysates of U251-MG cells plated at various cell densities were prepared by means of TCA protein precipitation and were subjected to western blot analysis. As shown in Fig. 3A, the expression levels of ACAT1 were highest at the cell density of $2.25 \times 10^{4}$ cells $/ \mathrm{cm}^{2}$, the density at which cells grew logarithmically. Immunocytochemistry confirmed that positive ACAT1 expression of U251-MG cells was highest at this cell density (Fig. 3B). These results suggested that ACAT1 expression in U251-MG cells depended on their cell growth state, being highest in exponentially proliferating cells.

ACAT1 inhibitor K604 reduces U251-MG cell proliferation. As ACAT1 expression in U251-MG cells depended on the cell density and proliferative state, the effect of the ACAT1 inhibitor K604 on the proliferation of U251-MG cells was examined. Of note, proliferation of cells at the low density (plated at $0.75 \times 10^{4}$ cells $/ \mathrm{cm}^{2}$ ) was significantly inhibited by K604 treatment $(\mathrm{P}<0.01)$ (Fig. 4A). However, K604 had no effect on the proliferation of U251-MG cells at medium and high cell densities (2.25-6.0x10 $\left.\mathrm{cells}_{\mathrm{s}} / \mathrm{cm}^{2}\right)$ (Fig. 4B-D).

ACAT1 inhibition deactivates ERK1/2 and Akt in U251-MG cells. To investigate the molecular mechanisms by which

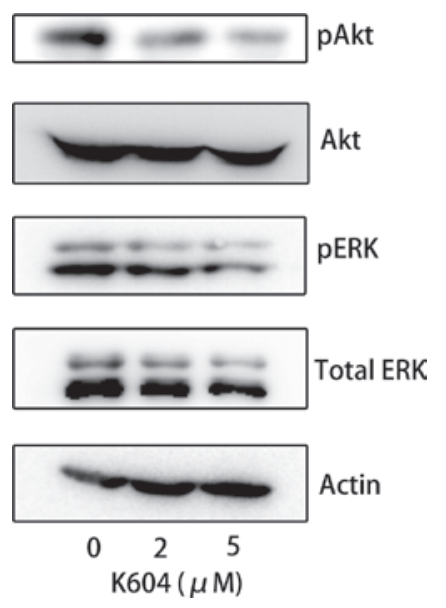

Figure 5. Acyl-CoA:cholesterol acyltransferase 1 inhibition suppresses the phosphorylation of Akt and ERK1/2. U251-MG cells plated at a density of $0.75 \times 10^{4}$ cells $/ \mathrm{cm}^{2}$ were cultured for $12 \mathrm{~h}$ and then treated with K604 (2 or $5 \mu \mathrm{M})$ for $24 \mathrm{~h}$. Cells were subjected to western blot analysis of Akt, pAkt, ERK and pERK. $\beta$-Actin was used as a loading control. p-ERK, phosphorylated extracellular signal-regulated kinase.

the ACAT1 inhibitor K604 suppressed glioblastoma-cell proliferation, the present study focused on the effects of K604 on the activation of ERK1/2 and Akt in U251-MG cells, as these two kinases reportedly regulate cell survival and proliferation of glioma, and affect the prognosis of patients with glioma (13,19-21). As K604 treatment effectively suppressed glioblastoma cell proliferation at the low cell density $\left(0.75 \times 10^{4}\right.$ cells $\left./ \mathrm{cm}^{2}\right)$ (Fig. 4), U251-MG cells plated at this density were treated with 0,2 or $5 \mu \mathrm{M} \mathrm{K} 604$ for $24 \mathrm{~h}$ and subjected to western blot analysis of the phosphorylation of Akt and ERK1/2. As shown in Fig. 5, K604 inhibited the phosphorylation of Akt and ERK1/2 in a dose-dependent manner (Fig. 5). 


\section{Discussion}

The present study showed that the selective ACAT1 inhibitor K604 effectively suppressed the proliferation of U251-MG glioblastoma cells. ACAT1 expression was highest in giloblastoma cells at the logarithmic growth phase. Furthermore, treatment with K604 downregulated the phosphorylation of Akt and ERK1/2. These results suggested that ACAT1 regulates glioblastoma-cell proliferation via modification of the Akt and/or the ERK1/2 pathway. A previous study demonstrated that the pharmacological ACAT inhibitor avasimibe suppressed glioblastoma-cell proliferation via increased apoptosis and cell cycle arrest (14). Avasimibe, which, in contrast to K604, inhibits the two ACAT isozymes ACAT1 and ACAT2, reduced the serum cholesterol levels by preventing apolipoprotein B-containing lipoprotein synthesis and secretion in minitiature pigs and transgenic mice $(22,23)$. Furthermore, avasimibe downregulated ACAT1 expression and cholesterol internalization and augmented cholesterol efflux in a dose-dependent manner in vitro (14). By contrast, K604 selectively inhibits ACAT1, and was shown to not affect the serum cholesterol levels, intracellular ACAT1 expression and cell cholesterol internalization and/or efflux (11). Therefore, the present study used the ACAT1-specific inhibitor K604 in order to study the molecular functions of ACAT1 in glioblastoma cell biology.

A number of studies previously established that Akt signaling is aberrantly activated in glioma and glioblastoma, which results in aggressive cell proliferation and a consequent poor clinical prognosis $(20,24,25)$. Akt inhibition effectively inhibited the growth of glioblastoma cells as well as glioblastoma-like stem cells (26). Furthermore, Chakravarti et al (20) reported that activation of the phosphatidylinositol 3-kinase-Akt pathway is significantly correlated with poor prognosis in patients with glioma (20). The ERK pathway, however, has been shown to be de-regulated in various human cancer types (27). A previous study demonstrated activation of the ERK pathway in human glioblastoma (20), and glioma cell proliferation was controlled via ERK1/2 activity (28). All of these results suggested that activation of Akt and ERK1/2 may be associated with refractory glioblastoma, which show resistance to clinical treatments due to radiation resistance and incomplete surgical resection. De-activation of the Akt and/or ERK1/2 pathway by the specific ACAT1 inhibitor K604 is a promising therapeutic application for this malignant tumor.

The molecular mechanisms of the inhibition of Akt and ERK1/2 phosphorylation by K604 have yet to be elucidated. It is widely accepted that the activation of Akt and ERK1/2 depends on the cellular cholesterol levels and the integrated function of lipid rafts, which are cholesterol-rich microdomains on the cell membrane $(29,30)$. Protein palmitoylation has a crucial role in raft localization of the proteins (31), and ACAT inhibition or ablation was shown to decrease raft localization of the amyloid precursor protein by reducing its palmitoylation (32). The hyaluronan receptor CD44, which is the principal molecule that determines the malignant behavior of glioblastoma $(33,34)$, was shown to be enriched in lipid rafts and to be reversibly palmitoylated $(35,36)$. Furthermore, it has been reported that CD44 activated Akt and ERK1/2 (35) and that CD44 knockdown altered Akt phosphorylation $(37,38)$. As the U251-MG cells and the glioblastoma tissues examined in the present study exhibited high expression of CD44 (data not shown), CD44 may have a crucial role in the growth of glioblastoma via modification of the Akt and/or ERK1/2 pathway. Alternatively, ACAT1 may affect signal transduction by inducing structural and functional changes in lipid rafts, as reported by Huang et al (39).

In conclusion, the present study demonstrated that K604 inhibited the proliferation of U251-MG cells and the phosphorylation of Akt and ERK1/2 in U251-MG cells. These results suggested that suppression of U251-MG-cell proliferation via pharmacological ACAT1 inhibition may be an attractive therapeutic strategy for refractory brain tumors. Future studies by our group will investigate this ACAT1-targeted therapeutic strategy in in vivo experiments in order to evaluate its potential for clinical application.

\section{Acknowledgements}

The authors would like to thank Ms. Hiroko Akita (Department of Human Pathology, Institute of Health Biosciences, University of Tokushima Graduate School) for her excellent technical assistance. The present study was supported by Grants-in-Aid for Scientific Research (no. C-23590448) and Challenging Exploratory Research (no. 26670190 to N.S.) from the Japan Society for the Promotion of Science (JSPS). The present study was also supported by the Support Center for Advanced Medical Sciences, Institute of Health Biosciences, The University of Tokushima Graduate School.

\section{References}

1. Roffo AH: Heliotropism of cholesterol in relation to skin cancer. Am J Cancer 17: 42-57, 1933.

2. Yasuda M and Bloor WR: Lipid content of tumors. J Clin Invest 11: 677-682, 1932.

3. Gebhard RL, Clayman RV, Prigge WF, Figenshau R, Staley NA, Reesey $\mathrm{C}$ and Bear A: Abnormal cholesterol metabolism in renal clear cell carcinoma. J Lipid Res 28: 1177-1184, 1987.

4. Rudel LL, Lee RG and Cockman TL: Acyl coenzyme A: Cholesterol acyltransferase types 1 and 2: Structure and function in atherosclerosis. Curr Opin Lipidol 12: 121-127, 2001.

5. Chang TY, Chang CC and Cheng D: Acyl-coenzyme A: Cholesterol acyltransferase. Annu Rev Biochem 66: 613-638, 1997.

6. Sakashita N, Miyazaki A, Takeya M, Horiuchi S, Chang CC, Chang TY and Takahashi K: Localization of human acyl-coenzyme a: Cholesterol acyltransferase-1 (ACAT-1) in macrophages and in various tissues. Am J Pathol 156: 227-236, 2000.

7. Nygren C, von Holst H, Månsson JE and Fredman P: Increased levels of cholesterol esters in glioma tissue and surrounding areas of human brain. Br J Neurosurg 11: 216-220, 1997.

8. Fredman P, von Holst H, Collins VP, Ammar A, Dellheden B, Wahren B, Granholm L and Svennerholm L: Potential ganglioside antigens associated with human gliomas. Neurol Res 8: 123-126, 1986.

9. Kaba SE and Kyritsis AP: Recognition and management of gliomas. Drugs 53: 235-244, 1997.

10. Maher EA, Furnari FB, Bachoo RM, Rowitch DH, Louis DN Cavenee WK and DePinho RA: Malignant glioma: genetics and biology of a grave matter. Genes Dev 15: 1311-1333, 2001.

11. Ikenoya M, Yoshinaka Y, Kobayashi H, Kawamine K, Shibuya K, Sato F, Sawanobori K, Watanabe T and Miyazaki A: A selective ACAT-1 inhibitor, K-604, suppresses fatty streak lesions in fat-fed hamsters without affecting plasma cholesterol levels. Atherosclerosis 191: 290-297, 2007. 
12. García-Regalado A, Guzmán-Hernández ML, Ramírez-Rangel I, Robles-Molina E, Balla T, Vázquez-Prado J and Reyes-Cruz G: G protein-coupled receptor-promoted trafficking of Gbeta1gamma2 leads to AKT activation at endosomes via a mechanism mediated by Gbeta1gamma2-Rab11a interaction. Mol Biol Cell 19: 4188-4200, 2008.

13. Zhang W and Liu HT: MAPK signal pathways in the regulation of cell proliferation in mammalian cells. Cell Res 12: 9-18, 2002.

14. Bemlih S, Poirier MD and El Andaloussi A: Acyl-coenzyme A: cholesterol acyltransferase inhibitor Avasimibe affect survival and proliferation of glioma tumor cell lines. Cancer Biol Ther 9: 1025-1032, 2010.

15. Chang CC, Chen J, Thomas MA, Cheng D, Del Priore VA, Newton RS, Pape ME and Chang TY: Regulation and immunolocalization of acyl-coenzyme A: Cholesterol acyltransferase in mammalian cells as studied with specific antibodies. J Biol Chem 270: 29532-29540, 1995.

16. Mosmann T: Rapid colorimetric assay for cellular growth and survival: Application to proliferation and cytotoxicity assays. J Immunol Methods 65: 55-63, 1983.

17. Niikura $\mathrm{Y}$, Nonaka $\mathrm{T}$ and Imajoh-Ohmi S: Monitoring of caspase-8/FLICE processing and activation upon Fas stimulation with novel antibodies directed against a cleavage site for caspase- 8 and its substrate, FLICE-like inhibitory protein (FLIP). J Biochem 132: 53-62, 2002.

18. Louis DN, Ohgaki H, Wiestler OD, Cavenee WK, Burger PC, Jouvet A, Scheithauer BW and Kleihues P: The 2007 WHO classification of tumours of the central nervous system. Acta Neuropathol 114: 97-109: 2007

19. Lawlor MA and Alessi DR: PKB/Akt: A key mediator of cell proliferation, survival and insulin responses? J Cell Sci 114 2903-2910, 2001

20. Chakravarti A, Zhai G, Suzuki Y, Sarkesh S, Black PM, Muzikansky A and Loeffler JS: The prognostic significance of phosphatidylinositol 3-kinase pathway activation in human gliomas. J Clin Oncol 22: 1926-1933, 2004.

21. Lopez-Gines C, Gil-Benso R, Benito R, Mata M, Pereda J Sastre J, Roldan P, Gonzalez-Darder J and Cerdá-Nicolás M: The activation of ERK1/2 MAP kinases in glioblastoma pathobiology and its relationship with EGFR amplification. Neuropathology 28: 507-515, 2008.

22. Burnett JR, Wilcox LJ, Telford DE, Kleinstiver SJ, Barrett PH, Newton RS and Huff MW: Inhibition of ACAT by avasimibe decreases both VLDL and LDL apolipoprotein B production in miniature pigs. J Lipid Res 40: 1317-1327, 1999.

23. Delsing DJ, Offerman EH, van Duyvenvoorde W, van Der Boom H, de Wit EC, Gijbels MJ, van Der Laarse A, Jukema JW, Havekes LM and Princen HM: Acyl-CoA:Cholesterol acyltransferase inhibitor avasimibe reduces atherosclerosis in addition to its cholesterol-lowering effect in ApoE*3-Leiden mice. Circulation 103: 1778-1786, 2001

24. Cheng CK, Fan QW and Weiss WA: PI3K signaling in glioma-anima models and therapeutic challenges. Brain Pathol 19: 112-120, 2009.
25. Robinson JP, Vanbrocklin MW, McKinney AJ, Gach HM and Holmen SL: Akt signaling is required for glioblastoma maintenance in vivo. Am J Cancer Res 1: 155-167, 2011.

26. Gallia GL, Tyler BM, Hann CL, Siu IM, Giranda VL, Vescovi AL, Brem H and Riggins GJ: Inhibition of Akt inhibits growth of glioblastoma and glioblastoma stem-like cells. Mol Cancer Ther 8: 386-393, 2009.

27. Reddy KB, Nabha SM and Atanaskova N: Role of MAP kinase in tumor progression and invasion. Cancer Metastasis Rev 22: 395-403, 2003

28. Chen D, Zuo D, Luan C, Liu M, Na M, Ran L, Sun Y, Persson A Englund E and Salford LG: Glioma cell proliferation controlled by ERK activity-dependent surface expression of PDGFRA. PLoS One 9: e87281, 2014.

29. Zhuang L, Lin J, Lu ML, Solomon KR and Freeman MR: Cholesterol-rich lipid rafts mediate akt-regulated survival in prostate cancer cells. Cancer Res 62: 2227-2231, 2002.

30. Ringerike T, Blystad FD, Levy FO, Madshus IH and Stang E: Cholesterol is important in control of EGF receptor kinase activity but EGF receptors are not concentrated in caveolae. J Cell Sci 115: 1331-1340, 2002.

31. Linder ME and Deschenes RJ: Palmitoylation: Policing protein stability and traffic. Nat Rev Mol Cell Biol 8: 74-84, 2007.

32. Bhattacharyya R, Barren C and Kovacs DM: Palmitoylation of amyloid precursor protein regulates amyloidogenic processing in lipid rafts. J Neurosci 33: 11169-11183, 2013.

33. Knüpfer MM, Poppenborg H, Hotfilder M, Kühnel K, Wolff JE and Domula M: CD44 expression and hyaluronic acid binding of malignant glioma cells. Clin Exp Metastasis 17: 71-76, 1999.

34. Wei KC, Huang CY, Chen PY, Feng LY, Wu TW, Chen SM, Tsai HC, Lu YJ, Tsang NM, Tseng CK, et al: Evaluation of the prognostic value of CD44 in glioblastoma multiforme. Anticancer Res 30: 253-259, 2010.

35. Ponta H, Sherman L and Herrlich PA: CD44: From adhesion molecules to signalling regulators. Nat Rev Mol Cell Biol 4: 33-45, 2003.

36. Oliferenko S, Paiha K, Harder T, Gerke V, Schwärzler C, Schwarz H, Beug H, Günthert U and Huber LA: Analysis of CD44-containing lipid rafts: Recruitment of annexin II and stabilization by the actin cytoskeleton. J Cell Biol 146: 843-854, 1999.

37. Subramaniam V, Vincent IR, Gardner H, Chan E, Dhamko H and Jothy S: CD44 regulates cell migration in human colon cancer cells via Lyn kinase and AKT phosphorylation. Exp Mol Pathol 83: 207-215, 2007

38. Park YS, Huh JW, Lee JH and Kim HR: shRNA against CD44 inhibits cell proliferation, invasion and migration and promotes apoptosis of colon carcinoma cells. Oncol Rep 27: 339-346, 2012.

39. Huang LH, Gui J, Artinger E, Craig R, Berwin BL, Ernst PA, Chang CC and Chang TY: Acatl gene ablation in mice increases hematopoietic progenitor cell proliferation in bone marrow and causes leukocytosis. Arterioscler Thromb Vasc Biol 33: 2081-2087, 2013. 